\title{
IT-Enabled Sustainable Supply Chain Management Capability Maturity
}

\author{
Xiang Peng \\ University of Melbourne \\ xiang.peng@student.unimelb.edu.au
}

\author{
Sherah Kurnia \\ University of Melbourne \\ sherahk@unimelb.edu.au
}

\author{
Tingru Cui \\ University of Melbourne \\ tingru.cui@unimelb.edu.au
}

\begin{abstract}
The increasing importance of sustainability gives rise to the sustainable supply chain management (SSCM). To help organizations develop their SSCM capabilities with IT support, this paper proposes an ITenabled sustainability supply chain management capability maturity model (SSCM CMM). Based on the previous literature, seven SSCM capabilities and four IT dimensions are identified. A five-level maturity model is then defined based on these two domains. The model is preliminarily examined through an in-depth case study with an Australian company. The case study reveals that the role played by IT is not fully recognized, the integration of IT function for sustainability into other organizational functions should be appropriately guided, and sustainability innovation capability deserves more attention. This study guides future research to systematically explore the role of IT and investigate the progression of ITenabled SSCM implementation and provides a useful tool for organizations to develop their SSCM capabilities with the support of IT.
\end{abstract}

\section{Introduction}

Given the growing emphasis on sustainability worldwide and the critical roles played by sustainable development for the survival of an organization [1,2], many organizations have spent much effort incorporating sustainability into their business operations. In the domain of supply chain management (SCM), the concept of sustainable supply chain management (SSCM) has emerged. Compared to traditional SCM, SSCM requires more efficient coordination among the supply chain partners since all the dimensions of sustainability, including economic, environmental and social (known as the triple bottom line, or TBL), should be adequately addressed $[3,4,5]$. Thus, in order to implement SSCM practices successfully, organizations should have matched SSCM capabilities [6]. Specifically, the advancement of technology has improved SCM significantly in the last two decades and has great potential to enable organizations to implement SSCM practices $[7,8,9$, 10]. Therefore, it is critical for organizations to have IT-enabled SSCM capability to stay competitive and to contribute to the global sustainability effort $[7,8]$.

Maturity models that focus on SSCM have been proposed to guide the organizations' journey towards sustainability [2]. It is noted that there exist two distinct lines of work. Specifically, a model that focuses on the need for various types of necessary organizational capabilities was developed [6]. However, this SSCM capability maturity model fails to link the capabilities to information technologies / information systems (IT/IS) capability needed for SSCM context. Moreover, in the realm of sustainability IT maturity models, a model for SSCM was also proposed [11]. Nevertheless, the IT maturity model for SSCM does not elaborate on how IT maturity relates to other types of organizational capabilities needed for SSCM. There has been an initial attempt to bridge these two lines of work where Eitiveni et al. [8] investigated how IT contributes to the development of the SSCM capabilities. However, how IT enables SSCM capabilities at different maturity levels still needs further investigation.

To bridge the gap analyzed above, this study is aimed at developing an IT-enabled SSCM maturity model that relates SSCM capability maturity to IT capability. The research question addressed in this study is: How can IT-enabled SSCM capability maturity level of organizations be defined? Specifically, two sub-questions are investigated:

a) What organizational capabilities are required to implement SSCM over time?

b) How does IT help organizations develop SSCM capabilities?

This study has two major phases: model development and model validation. First, an ITenabled SSCM capability maturity model is proposed based on the critical review of relevant literature. Then, in the second phase, the proposed model is preliminarily examined through a case study with one leading food and beverage manufacturer that has been proactive in sustainability implementation. It was 
found that the model is useful for assessing SSCM capability maturity.

The outline of this paper is as follows. The two domains of the model, SSCM capabilities and IT dimensions for sustainability, are synthesized based on the literature review. Next, an IT-enabled SSCM capability maturity model is proposed, and the expected IT capability for each SSCM capability maturity level is defined. Then the model is initially evaluated by an in-depth case study. Finally, we conclude the study, outline study limitations, and propose future research.

\section{Related work}

A literature review was conducted to inform the model development and understand the current state of the art in related research domains, including SSCM, SSCM capability, SSCM maturity, IT-enabled SSCM, sustainable IT/IS maturity and IT/IS capability. 119 papers that peer-reviewed and published in the past 10 years were selected from various databases, including Scopus, Emerald, EBSCO, and Web of Science. Besides, some most cited studies were also reviewed.

Since the scope of the proposed maturity model is IT-enabled capability, the literature review focused on two domains: SSCM capability and IT support.

\subsection{SSCM capabilities}

For the first domain, SSCM capability, we identified seven components. Five SSCM maturity models are analyzed to determine capabilities needed for SSCM implementation [5, 6, 12, 13, 14]. Among these models, many of them adopt a narrow scope, such as focusing on the sustainability disclosure capability [13]. The SSCM capability maturity model [6] is identified as the most comprehensive one as it covers all the capabilities analyzed by other studies. Therefore, we mainly adopt the classification of SSCM capabilities suggested by Kurnia et al. [6] (C1-C6 below). To ensure that the related capabilities are all covered, we improve the classification based on our analysis of other SSCM maturity models. Moreover, sustainability innovation capability (C7) is introduced. This capability is only indicated in the model proposed by Srai et al. [5]. However, this capability can bring significant value to organizations $[15,16]$ and is critical for achieving sustainability [17]. It can also be greatly enabled by IT [18]. Thus, this study defines seven types of SSCM capabilities as outlined below.

Cl: sustainability strategy and governance capability. This capability includes the organization's ability to design SSCM strategically, set specific SSCM objectives, and place effective governance $[5,6$,
12, 13]. Other capabilities are managed according to sustainability strategy and governance.

C2: sustainability data collection and sharing. Sustainability data collection and sharing is a basic but critical capability for organizations implementing SSCM practices $[6,12]$. It refers to the organization's ability to manage which data should be collected within and beyond the organization and which data should be shared with whom.

C3: sustainability training. This capability refers to the ability of the organization to evangelize sustainability within the organization and across its supply chain partners [6]. Organizations which have a high level of sustainability training capability will have all its employees and partners share the same value of sustainability, which helps strengthen the coordination among the whole supply chain.

C4: sustainability measurement and benchmarking capability. The organization should have the ability to measure its sustainability performance and compare with its sustainability goals and even with other organizations to ensure that SSCM practices are appropriately implemented and intended outcomes are obtained [6, 13].

C5: sustainability reporting capability. This capability refers to the ability to deliver valid and reliable reports that reflect the organization's current sustainability performance $[6,13]$. The reports can be made for internal use or for the public. Also, the content of the reports can be compulsory, such as those required by the regulatory government, or voluntary, such as those expected by customers, communities and other stakeholders.

C6: sustainability risk analysis capability. The organization's ability to identify and analyze possible unexpected outcomes of its supply chain initiatives is defined as risk analysis capability [6]. The risks can be tangible or intangible, measurable or unmeasurable. Apart from successfully analyze potential risks, organizations should also react to prevent undesirable results.

C7: sustainability innovation capability is the organization's ability to encourage and implement innovative supply chain processes, services or products that can improve its sustainability performance. This capability generally relies on the advancement in science and technology [5].

It is found that most existing studies either ignore the role of IT or only consider a technology or system independently (e.g., [7, 10]) instead of viewing IT as part of organizational capabilities (e.g., $[8,19])$ ). In fact, IT has several dimensions as discussed below and should be appropriately integrated with other organizational capabilities. 


\subsection{IT/IS capability dimensions}

As for the IT support domain, four components are defined. Three sustainable IT/IS maturity models are analyzed $[11,20,21]$. The models developed by Curry and Donnellan [20] and Rahim et al. [11] are the most comprehensive ones and cover all IS lifecycle stages noted by Standing and Jackson [21]. Thus, we draw on the aspects suggested by them, and propose the following IT capability dimensions for SSCM context.

D1: IT strategy and governance. This is the most prominent dimension of organizational IT capability. It guides all other dimensions to ensure that IT activities are aligned with SSCM goals. This dimension deals with the alignment between IT and SSCM, consisting of overall sustainable IT strategy, specific sustainable IT objectives and plans, policies, etc. [11, 20]. The maturity of this dimension can be assessed through the degree of formality and frequency of updating [11]. The more formal IT strategy and governance for SSCM are and the more frequent they are reviewed; the higher maturity level of this dimension is.

D2: IT process management. This dimension concerns with managing IT activities that are essential for the provision of IT services for SSCM. Related management activities cover analyzing, defining, implementing, monitoring and optimizing IT processes, and establishing measuring and reporting mechanisms [20]. Maturity assessment criteria include process formality and quality measurement and control [11]. To reach a higher maturity level of IT process management, organizations should improve the formalization of IT processes and their links with SSCM implementation initiatives and set more robust measuring and controlling mechanisms to ensure the quality of those processes.

D3: IT people and culture. In this dimension, people include all the individuals or groups that participate in the provision of IT services for SSCM, while culture refers to the shared value of IT in supporting SSCM within the organization and among the supply chain members $[11,20]$. The extent of people's understanding about IT process for supporting SSCM and the degree and formality of integration between IT and SSCM are used to identify the maturity level of this dimension [11].

D4: IT infrastructure. IT infrastructure refers to systems, applications, and databases that constitute the technical dimension of IT capability [11]. This dimension is also critical since the architecture of IT infrastructure can make a difference in the utilization of IT for SSCM context [11]. To support SSCM capabilities that are in a high maturity level, IT infrastructure should be well organized and widely used. A well-established IT infrastructure architecture does not only specify how IT infrastructure resources could be fully utilized for SSCM but is also flexible to address changes in SSCM practices, without incurring significant additional costs.

There are limited studies that analyze how IT viewed as organizational capability can support sustainability (e.g., [22, 23]), and many of them lack empirical validation (e.g., [11, 21]). Moreover, though Rahim et al. [11] focus on SSCM, the role of IT in enabling each SSCM capability is not specified.

\section{IT-enabled SSCM CMM}

The proposed IT-enabled sustainability supply chain management maturity model is shown in Table 1 . SSCM capability coverage of the supply chain and the extent of IT support are mainly used to define the level of maturity for each sustainability capability. As organizations achieve a higher maturity level, SSCM capability coverage and the extent of IT support increase. Organizations positioned in the three lowest maturity levels are more focused on improving the capabilities within the organization and IT provides support internally, while those positioned in the two highest maturity levels further develop their external sustainability capabilities and IT support extends to the external of organizations. As organizations move towards higher maturity levels, they need more support from IT [6]. For each maturity level, SSCM capability coverage and the support of the four IT dimensions are explained below.

Non-existent. No SSCM capabilities exist in this level, and IT capability dimensions (D1-D4) perform their roles independently in the organization without the consideration of SSCM.

Ad-hoc. SSCM capabilities are initially developed in limited business units. IT strategy and governance (D1) recognize the need to support SSCM. IT process management (D2) is linked to SSCM practices but on an ad hoc basis. Limited IT people and culture (D3) and infrastructure (D4) support SSCM practices.

Internally managed. SSCM capabilities are formally managed within the organization. IT strategy and governance (D1) are aligned with sustainability strategy and governance and are regularly reviewed. Specific IT processes (D2) are established for supporting SSCM. They are well-organized and regularly measured and reported within the organization. IT people (D3) assigned to support SSCM have specific and clear responsibilities. They are involved in the implementation of SSCM practices within the organization. As a result, IT culture (D3) and specific systems (D4), such as an electronic document management system (EDMS) [11] and a traceability system [24], are in place to support SSCM. 
Table 1. The proposed IT-enabled SSCM capability maturity model

\begin{tabular}{|c|c|c|c|c|c|}
\hline \multirow[b]{2}{*}{$\begin{array}{l}\text { IT-Enabled } \\
\text { SSCM } \\
\text { Capability }\end{array}$} & \multicolumn{5}{|c|}{ Level of Maturity } \\
\hline & $\begin{array}{c}\text { Non- } \\
\text { Existent }\end{array}$ & $\begin{array}{l}\text { Ad-Hoc } \\
\text { (Limited support } \\
\text { internally) }\end{array}$ & $\begin{array}{c}\text { Internally } \\
\text { Managed } \\
\text { (Adequate support } \\
\text { internally) } \\
\end{array}$ & $\begin{array}{c}\text { Externally } \\
\text { Integrated } \\
\text { (Involving key } S C \\
\text { partners) }\end{array}$ & $\begin{array}{c}\text { Optimized } \\
\text { (Involving all } S C \\
\text { partners) }\end{array}$ \\
\hline $\begin{array}{l}\text { C1: } \\
\text { Sustainability } \\
\text { strategy and } \\
\text { governance }\end{array}$ & \begin{tabular}{|l} 
No \\
sustainability \\
strategy and \\
governance. \\
No support \\
from IT \\
(strategy \& \\
governance, \\
process, \\
people \& \\
culture, and \\
infrastructure).
\end{tabular} & $\begin{array}{l}\text { No sustainability } \\
\text { strategy exists, } \\
\text { and sustainability } \\
\text { governance is } \\
\text { exercised within } \\
\text { limited business } \\
\text { units. } \\
\text { IT provides ad } \\
\text { hoc support to } \\
\text { sustainability } \\
\text { governance. }\end{array}$ & \begin{tabular}{|l|}
$\begin{array}{l}\text { Sustainability } \\
\text { strategy and } \\
\text { governance are } \\
\text { formally established } \\
\text { and exercised within } \\
\text { the organization. } \\
\text { IT formally } \\
\text { supports this } \\
\text { capability. }\end{array}$ \\
\end{tabular} & $\begin{array}{l}\begin{array}{l}\text { Sustainability } \\
\text { strategy is shared } \\
\text { with key supply } \\
\text { chain partners. }\end{array} \\
\text { IT supports } \\
\text { sustainability } \\
\text { strategy and } \\
\text { governance of the } \\
\text { organization and its } \\
\text { key supply chain } \\
\text { partners. }\end{array}$ & $\begin{array}{l}\text { Sustainability } \\
\text { strategy is shared } \\
\text { across the supply } \\
\text { chain. } \\
\text { IT supports shared } \\
\text { sustainability } \\
\text { strategy and } \\
\text { governance across } \\
\text { the supply chain. }\end{array}$ \\
\hline $\begin{array}{l}\text { C2: } \\
\text { Sustainability } \\
\text { data } \\
\text { collection and } \\
\text { sharing }\end{array}$ & $\begin{array}{l}\text { No } \\
\text { sustainability } \\
\text { data collection } \\
\text { and sharing. } \\
\\
\text { No support } \\
\text { from IT. }\end{array}$ & $\begin{array}{l}\text { Sustainability } \\
\text { data are collected } \\
\text { and shared in } \\
\text { limited business } \\
\text { units. } \\
\text { IT provides ad } \\
\text { hoc support to } \\
\text { sustainability data } \\
\text { collection and } \\
\text { sharing. }\end{array}$ & \begin{tabular}{|l|}
$\begin{array}{l}\text { Sustainability data } \\
\text { collection and } \\
\text { sharing are formally } \\
\text { exercised within the } \\
\text { organization. }\end{array}$ \\
IT formally \\
supports this \\
capability.
\end{tabular} & $\begin{array}{l}\text { Sustainability data of } \\
\text { the organization and } \\
\text { its key supply chain } \\
\text { partners are collected } \\
\text { and shared. } \\
\text { IT supports } \\
\text { sustainability data } \\
\text { collection and } \\
\text { sharing of the } \\
\text { organization and its } \\
\text { key supply chain } \\
\text { partners. }\end{array}$ & $\begin{array}{l}\text { Sustainability data } \\
\text { are collected and } \\
\text { shared across the } \\
\text { supply chain. } \\
\text { IT supports } \\
\text { sustainability data } \\
\text { collection and } \\
\text { sharing across the } \\
\text { supply chain. }\end{array}$ \\
\hline $\begin{array}{l}\text { C3: } \\
\text { Sustainability } \\
\text { training }\end{array}$ & $\begin{array}{l}\text { No } \\
\text { sustainability } \\
\text { training. } \\
\text { No support } \\
\text { from IT. }\end{array}$ & $\begin{array}{l}\text { Limited } \\
\text { sustainability } \\
\text { training is } \\
\text { provided. } \\
\text { IT provides ad } \\
\text { hoc support to } \\
\text { sustainability } \\
\text { training. }\end{array}$ & $\begin{array}{l}\text { Sustainability } \\
\text { training is formally } \\
\text { provided within the } \\
\text { organization. } \\
\text { IT formally } \\
\text { supports this } \\
\text { capability. }\end{array}$ & $\begin{array}{l}\text { Sustainability } \\
\text { training is provided } \\
\text { within the } \\
\text { organization and to } \\
\text { its key supply chain } \\
\text { partners. } \\
\text { IT supports } \\
\text { sustainability training } \\
\text { of the organization } \\
\text { and its key supply } \\
\text { chain partners. }\end{array}$ & $\begin{array}{l}\text { Sustainability } \\
\text { training is provided } \\
\text { within the } \\
\text { organization and to } \\
\text { all supply chain } \\
\text { partners. } \\
\text { IT supports } \\
\text { sustainability } \\
\text { training across the } \\
\text { supply chain. }\end{array}$ \\
\hline $\begin{array}{l}\mathrm{C} 4 \text { : } \\
\text { Sustainability } \\
\text { measurement } \\
\text { and } \\
\text { benchmarking }\end{array}$ & $\begin{array}{l}\text { No } \\
\text { sustainability } \\
\text { measurement } \\
\text { and } \\
\text { benchmarking. } \\
\text { No support } \\
\text { from IT. }\end{array}$ & $\begin{array}{l}\text { Sustainability } \\
\text { performance is } \\
\text { measured and } \\
\text { compared against } \\
\text { targets in limited } \\
\text { business units. } \\
\\
\text { IT provides ad } \\
\text { hoc support to } \\
\text { sustainability } \\
\text { measurement and }\end{array}$ & $\begin{array}{l}\text { Sustainability } \\
\text { performance is } \\
\text { measured and } \\
\text { compared against } \\
\text { organizational } \\
\text { targets. } \\
\text { IT formally } \\
\text { supports } \\
\text { sustainability } \\
\text { measurement and }\end{array}$ & $\begin{array}{l}\text { Sustainability } \\
\text { performance of the } \\
\text { organization and its } \\
\text { key supply chain } \\
\text { partners is measured } \\
\text { and compared against } \\
\text { that of key } \\
\text { competitors in the } \\
\text { market. } \\
\text { IT supports internal }\end{array}$ & $\begin{array}{l}\text { Sustainability } \\
\text { performance of the } \\
\text { organization and all } \\
\text { supply chain } \\
\text { partners is measured } \\
\text { and compared } \\
\text { against global } \\
\text { standards/goals } \\
\text { (e.g., ISO 14001 } \\
\text { standard). }\end{array}$ \\
\hline
\end{tabular}




\begin{tabular}{|c|c|c|c|c|c|}
\hline & & benchmarking. & benchmarking. & $\begin{array}{l}\text { and external } \\
\text { sustainability } \\
\text { measurement and } \\
\text { benchmarking } \\
\text { involving supply } \\
\text { chain partners. } \\
\end{array}$ & $\begin{array}{l}\text { IT supports external } \\
\text { sustainability } \\
\text { measurement across } \\
\text { the supply chain. }\end{array}$ \\
\hline $\begin{array}{l}\text { C5: } \\
\text { Sustainability } \\
\text { reporting }\end{array}$ & $\begin{array}{l}\text { No } \\
\text { sustainability } \\
\text { reporting. } \\
\text { No support } \\
\text { from IT. }\end{array}$ & $\begin{array}{l}\text { Sustainability } \\
\text { reporting exists in } \\
\text { limited business } \\
\text { units. } \\
\text { IT provides ad } \\
\text { hoc support to } \\
\text { sustainability } \\
\text { reporting. }\end{array}$ & $\begin{array}{l}\text { Sustainability } \\
\text { reporting exists in } \\
\text { every layer of } \\
\text { management within } \\
\text { the organization. } \\
\text { IT formally } \\
\text { supports } \\
\text { sustainability } \\
\text { reporting. }\end{array}$ & $\begin{array}{l}\text { Sustainability } \\
\text { reporting is available } \\
\text { from the organization } \\
\text { and its key supply } \\
\text { chain partners. } \\
\text { IT supports internal } \\
\text { and external } \\
\text { reporting involving } \\
\text { key supply chain } \\
\text { partners. }\end{array}$ & \begin{tabular}{|l} 
Sustainability \\
reporting is \\
available from the \\
organization and all \\
supply chain \\
partners. It \\
conforms with \\
global standards. \\
\\
IT supports internal \\
and external \\
reporting involving \\
all supply chain \\
partners.
\end{tabular} \\
\hline $\begin{array}{l}\text { C6: } \\
\text { Sustainability } \\
\text { risk analysis }\end{array}$ & $\begin{array}{l}\text { No } \\
\text { sustainability } \\
\text { risk analysis. } \\
\text { No support } \\
\text { from IT. }\end{array}$ & $\begin{array}{l}\text { Limited } \\
\text { sustainability risk } \\
\text { analysis is } \\
\text { conducted in } \\
\text { selected business } \\
\text { units. } \\
\text { IT provides ad } \\
\text { hoc support to } \\
\text { sustainability risk } \\
\text { analysis. }\end{array}$ & \begin{tabular}{|l} 
Sustainability risk \\
analysis is \\
conducted for \\
business units and \\
the organization as a \\
whole. \\
IT formally \\
supports \\
sustainability risk \\
analysis.
\end{tabular} & $\begin{array}{l}\text { Sustainability risk } \\
\text { analysis is extended } \\
\text { to the organization's } \\
\text { key supply chain } \\
\text { partners. } \\
\text { IT supports } \\
\text { sustainability risk } \\
\text { analysis of the } \\
\text { organization and its } \\
\text { key supply chain } \\
\text { partners. }\end{array}$ & $\begin{array}{l}\text { Sustainability risk } \\
\text { analysis is extended } \\
\text { to all supply chain } \\
\text { partners. } \\
\text { IT supports } \\
\text { sustainability risk } \\
\text { analysis across the } \\
\text { supply chain. }\end{array}$ \\
\hline $\begin{array}{l}\text { C7: } \\
\text { Sustainability } \\
\text { innovation }\end{array}$ & $\begin{array}{l}\text { No } \\
\text { sustainability } \\
\text { innovation. } \\
\text { No support } \\
\text { from IT. }\end{array}$ & $\begin{array}{l}\text { Sustainability } \\
\text { innovation is } \\
\text { launched in } \\
\text { limited business } \\
\text { units. } \\
\text { IT provides ad } \\
\text { hoc support to } \\
\text { sustainability } \\
\text { innovation. }\end{array}$ & $\begin{array}{l}\text { Sustainability } \\
\text { innovation is } \\
\text { promoted within the } \\
\text { organization. } \\
\text { IT formally takes } \\
\text { part in sustainability } \\
\text { innovation. }\end{array}$ & $\begin{array}{l}\begin{array}{l}\text { Sustainability } \\
\text { innovation involves } \\
\text { the organization's } \\
\text { key supply chain } \\
\text { partners. }\end{array} \\
\text { IT supports } \\
\text { sustainability } \\
\text { innovation within the } \\
\text { organization and } \\
\text { those innovations } \\
\text { involving key supply } \\
\text { chain partners. }\end{array}$ & $\begin{array}{l}\text { Sustainability } \\
\text { innovation is } \\
\text { promoted across the } \\
\text { supply chain. } \\
\text { IT supports } \\
\text { sustainability } \\
\text { innovation across } \\
\text { the supply chain. }\end{array}$ \\
\hline
\end{tabular}

Externally integrated. From this stage, SSCM capabilities extend to the external of the organization by involving key supply chain partners. IT strategy and governance (D1) also address sustainability needs beyond the organization. IT people (D3) should gain knowledge of the supply chain, the market and related global sustainability standards so that they can communicate with business stakeholders and know their needs for cooperating with key partners. IT processes (D2) and infrastructure (D4) are extended to connect with key partners' IT processes and infrastructure to enable and facilitate coordination. Overall, organizational IT function for sustainability is further developed and better integrates with other functions.

Optimized. At the highest maturity level, SSCM capabilities cover the whole supply chain network. IT strategy and governance (D1) are integrated within the 
supply chain network to support highly coordinated SSCM. IT people (D3) share their knowledge and support across the supply chain. IT processes (D2) are optimized within the organization. Besides, IT processes (D2) and infrastructure (D4) of the organization are further extended to link with those of all the supply chain partners. Overall, organizational IT function for sustainability is greatly integrated with other functions. At this stage, the organization may become a sustainability leader in the industry [20].

\section{Case study}

A case study is conducted to evaluate the applicability and the relevance of the proposed model. Specifically, an organization's IT-enabled SSCM capability maturity is assessed based on the model. Moreover, applying the model to a real-life context also helps us gain insights into the capabilities required for SSCM and investigate how IT support developing these capabilities.

\subsection{Overview of the case organization}

The case organization, AuFood (pseudonym), is one of the leading food and beverage companies in Australasia, having more than 7000 employees. It owns many famous brands in Australia and New Zealand and runs businesses globally. AuFood values sustainability as a key factor for its business, is motivated to develop its SSCM capabilities, and has adequate support to IT for facilitating SSCM capability development.

\subsection{Data collection}

The main sources of data for the case study are organizational documents and interviews [25]. First, we collected documentary materials to obtain an overview of the case organization's background, main businesses, and sustainability practices and performance. A primary data source is AuFood's most recent sustainability reports and other sustainabilityrelated information published on its official website. Besides, AuFood's parent company's most recent sustainability report was also referred to. Moreover, given that many programs supported by AuFood are run by third parties (such as REDcycle), we also looked for the information published by the third parties to learn more about what AuFood has done.

Then, two interviews were conducted with employees of AuFood. One is an initial interview, which covered the organization's overall sustainability initiatives, and the other is a semi-structured interview. There are three participants, including a sustainability manager, a data governance lead, and a master data steward. The basic information of the participants is shown in Table 2. An initial face-to-face conversation with Participant 1 and Participant 2, provided a highlevel overview of AuFood's business processes and sustainability initiatives. The second interview, which lasted about 90 mins, was arranged with Participants 2 and 3. They have long working experience at AuFood and showed great insights into the organization's SSCM. Before the interview, we sent the interviewees the intended interview questions, along with explanations of the terms including the four types of IT dimensions and seven types of SSCM capabilities. The interview session was held online via Zoom. A protocol was developed to guide the interview. It consists of general questions regarding organizational SSCM capabilities and specific questions regarding how IT enables each SSCM capability. They were also asked to rate AuFood maturity level for each ITenabled SSCM capability.

Table 2. Participants interviewed at AuFood

\begin{tabular}{|c|l|l|c|}
\hline Participants & \multicolumn{1}{|c|}{$\begin{array}{c}\text { Role in } \\
\text { AuFood }\end{array}$} & Experience & $\begin{array}{c}\text { No. of } \\
\text { Interviews }\end{array}$ \\
\hline Participant 1 & $\begin{array}{l}\text { Sustainability } \\
\text { Manager }\end{array}$ & 15 months & 1 \\
\hline Participant 2 & $\begin{array}{l}\text { Data } \\
\text { Governance } \\
\text { Lead }\end{array}$ & 11 years & 2 \\
\hline Participant 3 & $\begin{array}{l}\text { Master Data } \\
\text { Steward }\end{array}$ & 12 years & 1 \\
\hline
\end{tabular}

\subsection{Data analysis}

The analysis of the data went through five phases suggested by Yin [26]: compiling, disassembling, reassembling, interpreting, and concluding. First, both the document and interview data were systematically compiled. Then the coding method was used to disassemble the data. In the third phase, the data were reassembled and carefully investigated to check if there is any new pattern. Next, findings were interpreted to provide insight into the relationship between organizational IT capability and SSCM capabilities. At last, some conclusions were made, and the significance of this study was reflected.

\subsection{Research rigor}

We address research rigor by following the instructions provided by Yin [25]. Validity is established by conducting a thorough literature review in related areas, using multiple sources of evidence [25] and appropriately interpreting the collected data guided by the relevant concepts identified from the 
literature review, "so that the conclusions accurately reflect and represent the real world that was studied." [26, p.88] Reliability is addressed through the use of a case study protocol to guide the interviews, the use of case study repository to keep all research data including interview transcripts, data analysis procedures, and analyzed data [25].

\section{Case study findings}

\subsection{The organization's sustainability initiatives}

AuFood has implemented three major sustainability initiatives. First, the organization is devoted to providing products with better nutrition and encouraging responsible consumption. Therefore, AuFood not only reformulates its existing products but also invents innovative new products by utilizing its recipe system. Besides, the organization launches several online educational campaigns / programs for the public. The second sustainability initiative is to become more environmentally friendly and promoting responsible sourcing. AuFood advocates reuse, reduce, and recycle. It collects and shares sustainability data through sustainability systems and ERP. The organization also requests its suppliers to complete an online supply chain risk self-assessment. Finally, AuFood is committed to supporting local communities, suppliers, and employees. The relationships with local communities and suppliers are strengthened through several programs, both online and offline. As for the employees, safety is in the first place. Risks are monitored, measured, classified, and managed, and rigorous reporting system is established, involving all the layers of management.

\subsection{Maturity assessment}

AuFood's maturity level of each SSCM capability is assessed based on a five-point Likert scale, where 1 represents "non-existence" and 5 denotes "optimized". First, the participants were asked to score the maturity level for each IT-enabled SSCM capability. Second, based on both documentary data and the interview data, the researchers independently measured the maturity levels according to the criteria of the proposed model. Table 3 shows the overall scores given by the participants and the researchers.

The scores perceived by the participants are almost the same as those agreed by the researchers based on the proposed model, indicating that the proposed model is useful for capturing the maturity level of ITenabled SSCM capabilities. Though there are some capabilities marked slightly lower by the participants, it is probably because employees may not be fully aware of their company's SSCM capability and the level of IT support, while we have obtained more information from the documentary data analysis.

\section{Table 3. Scores of AuFood's IT-enabled SSCM capability maturity level}

\begin{tabular}{|l|c|c|}
\hline \multicolumn{1}{|c|}{$\begin{array}{c}\text { IT-enabled SSCM } \\
\text { capability }\end{array}$} & $\begin{array}{c}\text { Scores perceived } \\
\text { by participants }\end{array}$ & $\begin{array}{c}\text { Scores assessed } \\
\text { by researchers }\end{array}$ \\
\hline $\begin{array}{l}\text { C1: Sustainability } \\
\text { strategy and } \\
\text { governance }\end{array}$ & 4.5 & 4.5 \\
\hline $\begin{array}{l}\text { C2: Sustainability data } \\
\text { collection and sharing }\end{array}$ & 4 & 4 \\
\hline $\begin{array}{l}\text { C3: Sustainability } \\
\text { training }\end{array}$ & 4.5 & 4.5 \\
\hline $\begin{array}{l}\text { C4: Sustainability } \\
\text { measurement and } \\
\text { benchmarking }\end{array}$ & 4 & 4.5 \\
\hline $\begin{array}{l}\text { C5: Sustainability } \\
\text { reporting }\end{array}$ & 4 & 4 \\
\hline $\begin{array}{l}\text { C6: Sustainability risk } \\
\text { analysis }\end{array}$ & 4 & 4.5 \\
\hline $\begin{array}{l}\text { C7: Sustainability } \\
\text { innovation }\end{array}$ & 3 & 3.5 \\
\hline
\end{tabular}

Each IT-enabled SSCM capability of AuFood is briefly described below.

Sustainability strategy and governance. Both the participants and we mark AuFood's sustainability strategy and governance capability maturity 4.5 out of 5. It is found that AuFood has well-developed organizational sustainability strategy and governance and share them with key supply chain partners. Moreover, the organization aims to involve all its individual suppliers, which is still in progress. Accordingly, IT provides adequate support internally and shows the ability to serve more supply chain partners. Therefore, we identify the maturity level of this SSCM capability lies in between the externally integrated and optimized level.

Sustainability data collection and sharing. This capability scores 4 out of 5 , marked by both the participants and us. Sustainability data are collected and shared not only within AuFood but also with key supply chain partners, which are greatly enabled by IT. However, there is a lack of evidence indicating that most of the supply chain partners are involved, so this capability is assessed only at the fourth maturity level.

Sustainability training. Participants mark this capability 4.5 out 5 , which is agreed by us. AuFood provides scheduled sustainability training to both its employees and some key supply chain partners with the support of IT. The organization also plans to extend the training to more supply chain partners. Hence, the 
maturity of AuFood's sustainability training capability is between the external integrated and optimized level.

Sustainability measurement and benchmarking. This capability is rated 4 by the participants but 4.5 by us. Sustainability performance of AuFood is regularly measured and compared to global standards. Besides, AuFood also helps its supply chain partners assess their sustainability performance based on best-practice or global standards, which is supported by an online assessment tool. Moreover, AuFood's sustainability report suggests that AuFood continuously involves more supply chain partners in performance measurement and benchmarking. Hence, we identify this capability has reached the fourth maturity level and is moving towards the highest level.

Sustainability reporting. The participants and we score this capability 4 out of 5. AuFood's internal sustainability reporting is well-managed and largely supported by IT. Externally, AuFood publishes both regulatory and voluntary sustainability reports online, based on data collected and stored by related systems. Some data are provided by several key supply chain partners electronically. Though this capability shows some features of the optimized maturity level (the reporting conforms with national or global standards), it does not quite match the criteria of the external integrated maturity level (key supply chain partners are not directly involved). Therefore, we assess this capability at the fourth level overall.

Sustainability risk analysis. For this capability, our score is slightly higher than the participants (4.5 vs. 4 ). Sustainability risk analysis is performed both within the organization and with key supply chain partners. Also, it is found in the sustainability report that AuFood has been inviting more supply chain partners to do the risk assessment. IT supports this capability by collecting related data and providing an assessment tool. Hence, we score AuFood's sustainability risk analysis capability maturity level between external integrated and optimized levels.

Sustainability innovation. We mark AuFood's sustainability innovation maturity 3.5 out of 5 . The organization promotes products innovation within the organization with the support of IT. However, key supply chain partners are not involved. Only limited suppliers joined in the sustainable packaging innovation project. It seems that the participants are only aware of their product innovation, so they only rate this capability 3 .

\section{Discussion}

\subsection{Addressing research questions}

RQ: How can IT-enabled SSCM capability maturity level of organizations be defined? IT-enabled SSCM capability has two main domains, SSCM capability and IT support. Organizations develop their SSCM capability to help them implement SSCM practices. IT capability is recognized as a critical enabler for SSCM capability. Hence, the proposed IT-enabled SSCM capability maturity model incorporates the two domains. Based on SSCM capability coverage and the extent of IT support, IT-enabled SSCM capability maturity of organizations can be defined into five levels (see Table 1).

Sub-RQ1: What organizational capabilities are required to implement SSCM over time? SSCM capability is the first domain of the proposed model. The model lists seven organizational capabilities for SSCM implementation, which have been validated using a single case study, and no other capability have been identified. At the initial stage, organizations should first focus on their internal capability for all the dimensions. Before SSCM capabilities are formalized and managed within the organization, they are only developed in limited business units. Next, organizations should then develop their external SSCM capabilities. Key supply chain partners are firstly involved, then SSCM capabilities are further extended to more partners. At the optimal level, organizational SSCM capabilities cover the whole organization and all the partners within the supply chain network.

Sub-RQ2: How does IT help organizations develop SSCM capabilities? IT support is the second domain of the proposed model. Four dimensions of IT are identified in the literature review. The support from IT strategy and governance (D1) is prominent, especially when organizations reach high-level maturity. Other aspects of IT must be appropriately guided by the IT strategy and governance to support both internal and external SSCM. In terms of IT people and culture (D2), they are critical for bringing new ideas and realizing services desired by SSCM. At the operational level, IT processes and infrastructure (D3 \& D4) enable SSCM capabilities by providing specific services.

Regarding the applicability of the model, we believe that, based on the case study, the model is useful for assessing SSCM capability maturity. The SSCM capabilities are clear and identifiable. The assessment criteria are generic while sufficient for capturing the maturity level of the case organization, so there are no changes to the model based on our preliminary validation. However, some of the IT dimensions are not always easily assessable. This may because the role of IT is underestimated and not fully recognized by the organization and its employees. IT support is not addressed in the sustainability reports, and the participants have limited knowledge about how 
sustainability practices are enabled by IT. Nevertheless, our study offers modest contributions to research and practice as outlined below.

\subsection{Study Contributions}

IT-enabled SSCM is still in its infancy as a research topic. Based on the SSCM capability maturity model developed by Kurnia et al. [6], this study further extends the model by introducing sustainability innovation capability and capturing the support of IT at each maturity level. Thus, the revised model proposed in this study has more complete dimensions and incorporates IT capability specifically.

Moreover, existing sustainable IT maturity models are not directly connected to SSCM capabilities and lack empirical validation. Drawing on Curry and Donnellan [20] and Rahim et al. [11], we refine the IT dimensions and relate them to SSCM capability for each maturity level. Besides, the proposed model is validated preliminarily through an in-depth case study.

This study also indicates that the role played by IT is not fully recognized. Many existing SSCM studies merely discuss IT infrastructure dimension. Also, though AuFood views IT as an enabler for its SSCM, when it comes to SSCM innovation, only a basic system (i.e., D4 infrastructure dimension) was involved. In fact, organizational IT capability, including all the dimensions, can make significant contributions to sustainability innovation [18].

In terms of practical contribution, this study provides organizations with a useful tool to guide their IT-enabled SSCM capability development. Specifically, by referring to the model, organizations can evaluate and benchmark their current SSCM capabilities. The model serves as a roadmap that guides organizations to improve their SSCM capabilities with IT support.

Besides, this study reveals that the integration of IT function for sustainability into other organizational functions should be appropriately guided. In the case study, AuFood's IT function was not well integrated into its sustainability reporting function. To better organize the IT function and improve SSCM capabilities, organizations are recommended to have an IT management roadmap or enterprise architecture.

Finally, this study highlights that sustainability innovation deserves more attention. In the case study, sustainability innovation capability scores the lowest mark. However, IT-enabled sustainability innovation can make a great impact on organizational sustainability performance [18]. Thus, organizations should develop their sustainability innovation capability to achieve higher maturity level of SSCM.

\section{Conclusion}

This study proposes a comprehensive IT-enabled SSCM capability maturity model by refining previous maturity models $[6,11,20]$ and preliminarily validates the model through an in-depth case study. This study bridges the research gap by developing an IT-enabled SSCM capability maturity model. It addresses the importance of SSCM capability and emphasizes IT support for SSCM capability development. This study also emphasizes that the role played by IT needs to be fully recognized because IT as a capability can impacts nearly all the aspects of the supply chain. For practice, organizations can use the proposed model to improve their SSCM capabilities by utilizing their IT capability. Also, the case study indicates that, when supporting SSCM, IT function sometimes is not appropriately integrated with other organizational functions. Third, this study recognizes sustainability innovation as a critical SSCM capability, which deserves more attention. It is believed that sustainability innovation helps organizations improve their sustainability performance and brings competitive advantages.

This study has the following limitations. The development of the model usually involves interviews with experts or organizations to determine SSCM capability aspects [27, 28]. Since we developed the model by adapting and combining three existing models identified in the literature, this limitation should not be significant. Moreover, how each IT dimension enables each SSCM capability is not articulated in the study. The proposed model only gives a high-level view of IT support. In addition, limited participants were involved, which might have affected the overall maturity assessment. Also, the proposed model is only evaluated using a single case study, limiting the generalizability of the findings.

Future work could conduct multiple case studies that involve more organizations from different industries and more participants from various parties to further evaluate and refine the proposed model. This study could also be complemented by investigating how each of the IT dimensions impacts SSCM capabilities specifically. This study lays the foundation for future research to investigate the progression of ITenabled SSCM capability development of an organization and further analyze the importance of sustainability innovation capability in the overall development of SSCM maturity.

\section{References}

[1] Müller, A.L. and Pfleger, R., "Business Transformation Towards Sustainability", Business Research, 7(2), 2014, pp. 313-350. 
[2] Correia, E., Carvalho, H., Azevedo, S., and Govindan, K., "Maturity Models in Supply Chain Sustainability: A Systematic Literature Review", Sustainability, 9(1), 2017, p. 64.

[3] Seuring, S. and Müller, M., "From a Literature Review to a Conceptual Framework for Sustainable Supply Chain Management", Journal of Cleaner Production, 16(15), 2008, pp. 1699-1710.

[4] Gold, S., Seuring, S., and Beske, P., "Sustainable Supply Chain Management and Inter-Organizational Resources: A Literature Review", Corporate Social Responsibility and Environmental Management, 17(4), 2010, pp. 230-245.

[5] Srai, J.S., Alinaghian, L.S., and Kirkwood, D.A. "Understanding Sustainable Supply Network Capabilities of Multinationals: A Capability Maturity Model Approach", Journal of Engineering Manufacture, 227(4), 2013, pp. 595-615.

[6] Kurnia, S., Rahim, M.M., Samson, D., and Singh, P. "Sustainable Supply Chain Management Capability Maturity: Framework Development and Initial Evaluation", The 22 $2^{\text {nd }}$ European Conference on Information Systems, Tel Aviv, Israel, 2014.

[7] Sanders, N.R., Boone, T., Ganeshan, R., and Wood, J.D., "Sustainable Supply Chains in the Age of AI and Digitization: Research Challenges and Opportunities", Journal of Business Logistics, 40(3), 2019, pp. 229-240.

[8] Eitiveni, I., Kurnia, S., and Buyya, R. "IT-Enabled Capabilities for Sustainable Supply Chain Management: An Affordance Theory Perspective", The 22 ${ }^{\text {nd }}$ Pacific Asia Conference on Information Systems, Yokohama, Japan, 2018.

[9] Dhanorkar, S., Kim, Y., and Linderman, K., "An Empirical Investigation of Transaction Dynamics in Online Surplus Networks: A Complex Adaptive System Perspective", Journal of Operations Management, 65(2), 2019, pp. 160-189.

[10] Kouhizadeh, M., Saberi, S., and Sarkis, J., "Blockchain Technology and the Sustainable Supply Chain: Theoretically Exploring Adoption Barriers", International Journal of Production Economics, 231, 2021, p. 107831.

[11] Rahim, M.M., Kurnia, S., Singh, P., and Samson, D. "Developing an IT Maturity Model for Sustainable Supply Chain Management Implementation", The $18^{\text {th }}$ Pacific Asia Conference on Information Systems, Chengdu, China, 2014.

[12] Helene Seidel-Sterzik, Sarah McLaren, and Garnevska, E., "A Capability Maturity Model for Life Cycle Management at the Industry Sector Level", Sustainability, 10(7), 2018, p. 2496.

[13] Okongwu, U., Morimoto, R., and Lauras, M., "The Maturity of Supply Chain Sustainability Disclosure from a Continuous Improvement Perspective", International Journal of Productivity and Performance Management, 62(8), 2013, pp. 827-855.

[14] Reefke, H., Ahmed, M.D., and Sundaram, D., "Sustainable Supply Chain Management-Decision Making and Support: The SSCM Maturity Model and System", Global Business Review, 15(4S), 2014, pp. $1 \mathrm{~S}-12 \mathrm{~S}$.
[15] Gloet, M. and Samson, D. "Supporting Supply Chain Innovation and Sustainability Practices through Knowledge and Innovation Management", The 53 ${ }^{\text {rd }}$ Hawaii International Conference on System Sciences, Maui, Hawaii, 2020.

[16] Samson, D. and Gloet, M., Innovation and Entrepreneurship: Creating New Value, Victoria Oxford University Press, South Melbourne, Australia 2015.

[17] Kusi-Sarpong, S., Gupta, H., and Sarkis, J., "A Supply Chain Sustainability Innovation Framework and Evaluation Methodology", International Journal of Production Research, 57(7), 2019, pp. 1990-2008.

[18] Kurnia, S., Rahim, M.M., Samson, D., and Sedera, D. "Exploring ICT-Enabled Sustainability Innovations Development: A Conceptual Study", The $23^{\text {rd }}$ Pacific Asia Conference on Information Systems, Xi'an, China, 2019.

[19] Carrera Rivera, A. and Kurnia, S. "Exploring the Roles of ICT in Supporting Sustainability Practices", The $26^{\text {th }}$ Australasian Conference on Information Systems, Adelaide, Australia, 2015.

[20] Curry, E. and Donnellan, B., Understanding the Maturity of Sustainable ICT, in Green Business Process Management: Towards the Sustainable Enterprise, Springer Berlin Heidelberg: Berlin, Heidelberg, 2012, pp. 203-216.

[21] Standing, C. and Jackson, P., "An Approach to Sustainability for Information Systems", Journal of Systems and Information Technology, 9(2), 2007, pp. 167-176.

[22] Donnellan, B., Sheridan, C., and Curry, E., "A Capability Maturity Framework for Sustainable Information and Communication Technology", IT Professional, 13(1), 2011, pp. 33-40.

[23] Kurnia, S., Rahim, M.M., and Gloet, M. "Understanding the Roles of IS/IT in Sustainable Supply Chain Management", The $16^{\text {th }}$ Pacific Asia Conference on Information Systems, Ho Chi Minh, Vietnam, 2012.

[24] Eitiveni, I., Kurnia, S., and Buyya, R. "Exploring How a Traceability System Enables Sustainability Transformation in the Food Supply Chain: An Affordance Theory Perspective", The $27^{\text {th }}$ European Conference on Information Systems, Stockholm and Uppsala, Sweden, 2019.

[25] Yin, R.K., Case Study Research and Applications: Design and Methods, 6 ed, SAGE Publications Los Angeles, 2018.

[26] Yin, R.K., Qualitative Research from Start to Finish, $2^{\text {nd }}$ ed, The Guilford Press, New York, 2015.

[27] Becker, J., Knackstedt, R., and Pöppelbuß, J., "Developing Maturity Models for IT Management", Business \& Information Systems Engineering, 1(3), 2009, pp. 213-222.

[28] de Bruin, T., Freeze, R., Kulkarni, U., and Rosemann, M. "Understanding the Main Phases of Developing a Maturity Assessment Model", The $16^{\text {th }}$ Australasian Conference on Information Systems, Sydney, Australia, 2005 . 